\title{
Basophil Band Form to Leukocytes Ratio Measurement
}

National Cancer Institute

\section{Source}

National Cancer Institute. Basophil Band Form to Leukocytes Ratio Measurement. NCI

Thesaurus. Code C130155.

The determination of the ratio of band basophils compared to leukocytes in a sample.

The measurement may be expressed as a ratio or percentage. 